
covas. Horticultura Brasileira 25:247-251.

\title{
Produtividade de cultivares de cebola em função do número de mudas por célula de bandeja e espaçamento entre covas
}

\author{
Pablo Forlan Vargas ${ }^{1}$; Leila Trevizan Braz'; André May ${ }^{2}$ \\ ${ }^{1}$ UNESP-FCAV, Depto. Produção Vegetal, Via de acesso Prof. Paulo Donato Castellane, s/n, 14884-900 Jaboticabal-SP; ${ }^{2}$ IAC/Campinas, \\ Pesquisador; pfvargas@fcav.unesp.br
}

\section{RESUMO}

Objetivando avaliar a produtividade de cultivares de cebola em função do espaçamento entre covas e número de mudas por célula de bandeja, foi instalado um experimento na região de São José do Rio Pardo-SP. O delineamento experimental utilizado foi de blocos ao acaso, em esquema fatorial $2 \times 2 \times 3$, com quatro repetições. Os fatores avaliados foram os híbridos Princesa e Superex, duas e três mudas por célula de bandeja e espaçamentos entre covas de $8,12 \mathrm{e}$ $14 \mathrm{~cm}$. A produtividade foi influenciada apenas pelo fator cultivar, sendo que 'Superex' $\left(68,9 \mathrm{t} \mathrm{ha}^{-1}\right)$ produziu $33,1 \%$ a mais que 'Princesa' $\left(51,7 \mathrm{tha}^{-1}\right)$. Conclui-se que a cultivar Superex apresentou maior produtividade em relação à 'Princesa' e que a maior massa de bulbos foi obtida no espaçamento entre covas de $14 \mathrm{~cm}$ com duas mudas por célula de bandeja em ambas cultivares.

Palavras-chave: Allium cepa, densidade de plantas, distribuição espacial, transplante.

\begin{abstract}
Yield of onion cultivars as a result of the number of seedlings per cell tray and within hole spacing

The yield of onion cultivars was evaluated as a result of within row spacing and number of seedlings per cell tray. The experiment was performed in São José do Rio Pardo, São Paulo State, Brazil. The experimental design was of randomized blocks, and the treatments were arranged in a factorial scheme $2 \times 2 \times 3$, with four replicates. The evaluated factors were two hybrids Princesa and Superex; two and three seedlings transplants per tray cell and three within hole spacing of 8,12 and $14 \mathrm{~cm}$. Bulb yield was influenced only by the cultivar factor, being 'Superex' (68,9 t ha-1) 33,1\% superior than 'Princesa' $\left(51,7 \mathrm{t} \mathrm{ha}^{-1}\right)$. The cultivar Superex presented higher yield in relation to 'Princesa' and a greater bulb mass was obtained when adopting the hole spacing of $14 \mathrm{~cm}$ with two seedlings transplants per tray cell in the two cultivars.
\end{abstract}

Keywords: Allium cepa, plants density, spatial distribution, transplant.

\section{(Recebido para publicação em 22 de fevereiro de 2006; aceito em 8 de março de 2007)}

\begin{abstract}
A cebola (Allium cepa L.) é um dos produtos olerícolas de maior importância no Brasil, suplantada apenas pelo tomate e pela batata (Cardoso \& Costa, 1999). Os maiores produtores mundiais são a China (17.544.660 t), a Índia (5.000.000 t), e os Estados Unidos (3.162.750 t), sendo o Brasil o nono maior produtor (FNP Consultoria e Comércio, 2005).
\end{abstract}

A produção brasileira, em 2004, foi de 1.153.237 t, em uma área de 58.611 ha, o que resulta em uma produtividade média de 20,0 t ha-1 . O estado de São Paulo possui a segunda maior produtividade (28,0 t ha-1) e produção (200.800 t) do País (FNP Consultoria e Comércio, 2005). As principais regiões produtoras de São Paulo são os municípios de Piedade, São José do Rio Pardo e Monte Alto (Minami \& Tessarioli Netto, 1994; Vidigal et al., 2002).

Em São Paulo, a safra de cebola compreende o período de junho a dezembro; para tanto, o estado possui épocas e sistemas de cultivos distintos. Co- lheitas precoces são obtidas pelo sistema de cultivo de bulbinhos, sendo o maior volume oriundo de transplante de mudas (May, 2006).

Atualmente, a cultura tem se expandido com o aparecimento de novas áreas de produção, principalmente em Goiás, Distrito Federal e Minas Gerais, tendo acarretado o crescimento da oferta anual de cebola. Assim, novos sistemas de cultivo têm sido introduzidos visando à oferta em épocas de escassez do produto, bem como a melhoria da produtividade e qualidade do bulbo e, como conseqüência, a redução dos custos de produção, visto que a margem de lucro é cada vez menor (Vargas, 2005).

Ferreira (2000) cita que alguns produtores, ao invés de utilizarem mudas provenientes de canteiros, produzem mudas em bandejas de poliestireno de 288 células; em geral, o transplante ocorre com três plantas por célula.

A utilização de mudas produzidas em bandejas pode antecipar a colheita, pois, sendo a produção realizada em ambiente protegido, essa pode coincidir com o período chuvoso do ambiente natural, que pode ser prejudicial. No sistema convencional de produção de mudas de raiz nua e da semeadura direta de cebola, há necessidade de se aguardar o término do período chuvoso para dar início à implantação da cultura (Vargas, 2005).

Culturas estabelecidas com mudas de bandejas, além do menor ciclo, geralmente exigem menos irrigações, pulverizações e tratos culturais (Fontes \& Silva, 2002), menor gasto com sementes, obtenção de mudas mais vigorosas e com melhor uniformidade. Aliado a isto, existe a possibilidade da produção de mais de uma muda por célula de bandeja, o que vem contribuir para a redução do custo por muda produzida (Ferreira, 2000).

Com a introdução desta nova tecnologia de produção de mudas em bandejas com mais de uma muda por célula, algumas dificuldades têm surgido, como a escolha ideal do espaçamento 
entre covas para diferentes números de mudas por célula, pois, até o momento, não há trabalhos que estabeleçam espaçamentos ideais para diferentes números de mudas por célula.

As melhores remunerações são obtidas pelos bulbos classificados como médios (50 a 70 mm de diâmetro, classificados como das classes 3 e 3 cheio). Dessa forma, distribuições espaciais de plantas visando a atender a essa demanda, tornam-se necessárias. De acordo com a população de plantas na área, a competição por água, luz e nutrientes faz com que o tamanho dos bulbos e a produtividade total variem (Nichols, 1967). Assim, o estudo do espaçamento entre covas, em função do número de mudas por célula, torna-se de grande importância. O objetivo deste trabalho foi avaliar a produtividade e a massa de bulbos de cebola em função do espaçamento entre covas e do número de mudas por célula de bandeja, em duas cultivares de cebola.

\section{MATERIAL E MÉTODOS}

O experimento foi conduzido no município de São José do Rio Pardo (SP), a $21^{\circ} 35^{\prime}$ de latitude sul e $43^{\circ} 53^{\prime}$ de longitude oeste, na Fazenda Santa Manoela, com uma altitude aproximada de $900 \mathrm{~m}$. O clima encontra-se em área de transição dos tipos Aw e Cwa, segundo classificação de Köppen, com verão chuvoso e inverno seco, com precipitação anual entre 1.100 a 1.700 mm.

Análises química e física do local do experimento, realizadas na UNESPFCAV, apresentaram: $\mathrm{pH}$ em $\mathrm{CaCl}_{2}=5,7$; $\mathrm{MO}=18,0 \mathrm{~g} \mathrm{dm}^{-3} ; \mathrm{P}_{\text {resina }}=191,0 \mathrm{mg} \mathrm{dm}^{-3}$; $\mathrm{K}=3,8 \mathrm{mmol}_{\mathrm{c}} \mathrm{dm}^{-3} ; \mathrm{Ca}=62,0 \mathrm{mmol}_{\mathrm{c}} \mathrm{dm}^{-3}$; $\mathrm{Mg}=30,0 \mathrm{mmol}_{\mathrm{c}} \mathrm{dm}^{-3} ; \mathrm{H}+\mathrm{Al}=22,0$ mmol $\mathrm{dm}^{-3} ; \mathrm{SB}=95,8 \mathrm{mmol}_{\mathrm{c}} \mathrm{dm}^{-3}$; $\mathrm{T}=117,8 \mathrm{mmol} \mathrm{dm}^{-3} ; \mathrm{V} \%=81,0$; argila $=410,0 \mathrm{~g} \mathrm{~kg}^{-1}$; limo $=150,0 \mathrm{~g} \mathrm{~kg}^{-1}$; areia fina $=200,0 \mathrm{~g} \mathrm{~kg}^{-1}$ e areia grossa $=240,0$ $\mathrm{g} \mathrm{kg}^{-1}$, sendo o solo classificado como argiloso.

O preparo do solo constou de uma aração e duas gradagens. Os canteiros foram levantados com auxílio de um rotoencanteirador, à altura de $15 \mathrm{~cm}$, tendo a largura do canteiro $1,5 \mathrm{~m}$ de base e 1,2 $\mathrm{m}$ de topo.

A adubação de plantio foi realizada seguindo as recomendações de Trani et al. (1996), fornecendo por hectare 30,0 $\mathrm{kg}$ de $\mathrm{N}, 90,0 \mathrm{~kg}$ de $\mathrm{P}_{2} \mathrm{O}_{5}$ e $60,0 \mathrm{~kg}$ de $\mathrm{K}_{2} \mathrm{O}$, sendo aplicada toda a dose sobre os canteiros e incorporada com auxílio do rotoencanteirador.

A semeadura ocorreu em 06/03/04, em bandejas de poliestireno expandido de 288 células, preenchidas com substrato Plantmax $\mathrm{HT}^{\circledR}$, sendo semeadas quatro sementes por célula de bandeja, com posterior desbaste, em casa de vegetação, sendo irrigadas diariamente. O transplante ocorreu 32 dias após, quando as mudas se encontravam com 15,0 cm de altura e cerca de 5,0 $\mathrm{mm}$ de diâmetro do pseudocaule. $\mathrm{O}$ transplante ocorreu no final da tarde com o solo umedecido.

$\mathrm{O}$ delineamento experimental foi de blocos ao acaso, em esquema fatorial $2 \mathrm{x}$ $2 \times 3$, com quatro repetições. Os fatores avaliados foram os híbridos Princesa e Superex, duas e três mudas por célula de bandeja e espaçamentos entre covas de $8 ; 12$ e $14 \mathrm{~cm}$, caracterizando seis arranjos de plantio: 2 plantas por célula $\times 8$ cm entre covas $\left(83,3\right.$ plantas $\left.\mathrm{m}^{-2}\right)$; 2 plantas por célula $\mathrm{x} 12 \mathrm{~cm}$ entre covas $(55,5$ plantas $\left.\mathrm{m}^{-2}\right) ; 2$ plantas por célula $\mathrm{x} 14 \mathrm{~cm}$ entre covas $\left(47,6\right.$ plantas $\left.\mathrm{m}^{-2}\right) ; 3$ plantas por célula x $8 \mathrm{~cm}$ entre covas (125,0 plantas $\left.\mathrm{m}^{-2}\right) ; 3$ plantas por célula $\mathrm{x} 12 \mathrm{~cm}$ entre covas $\left(83,3\right.$ plantas $\left.\mathrm{m}^{-2}\right)$, e 3 plantas por célula x $14 \mathrm{~cm}$ entre covas $(71,4$ plantas $\mathrm{m}^{-2}$ ). Cada parcela teve quatro linhas com espaçamento de $0,3 \mathrm{~cm}$, comprimento $2,5 \mathrm{~m}$ e largura de $1,2 \mathrm{~m}$, perfazendo área total da parcela de $3,0 \mathrm{~m}^{2}$. A área total do experimentou ocupou cerca de 204,0 $\mathrm{m}^{2}$.

A marcação das distâncias entre covas foi realizada com auxílio de três furadores, correspondentes às distâncias entre covas de $8 ; 12$ e 14 cm. O transplante foi realizado utilizando-se duas e três mudas por cova. As adubações de cobertura foram realizadas aos 21 e 50 dias após o transplante, fornecendo em cada uma delas $25,0 \mathrm{~kg}$ de $\mathrm{Ne} \mathrm{K}_{2} \mathrm{O}$ através de $125,0 \mathrm{~kg} \mathrm{ha}^{-1}$ da formulação 20 00-20. O controle de pragas e doenças foi realizado de acordo com a necessidade da cultura, assim como as capinas manuais para o controle de plantas daninhas. As irrigações foram feitas pelo sistema de aspersão convencional, conforme a necessidade da cultura.
As características das cultivares utilizadas são: Princesa, híbrido de dias curtos, ciclo de 130-150 dias, catáfila dourada, fechamento de talo firme, formato arredondado e bulbos uniformes, com centro único; folhagem muito vigorosa; excelente resistência à raiz rosada e boa capacidade de armazenamento (SEMINIS, s.d.); Superex, híbrido precoce de ciclo curto (120 dias), formato redondo baixo, bulbo de pouca catáfila, de coloração clara, pouco pungente; porte baixo, folhas com menor cerosidade que a cultivar Princesa (TAKII, s.d.).

A colheita ocorreu, em 1,0 m linear das duas fileiras centrais $\left(0,6 \mathrm{~m}^{2}\right)$ em $25 /$ 08/04, quando $75 \%$ das plantas de todo o experimento "estalaram", sendo arrancadas manualmente e dispostas no solo para o processo de cura a campo, permanecendo por dois dias. Após a cura avaliaram-se a produtividade e a massa do bulbo ( $\mathrm{g}$ bulbo ${ }^{-1}$ ), calculada pela divisão da massa total de bulbos coletados por área útil da parcela pelo número total de bulbos da parcela. Na Figura 1, são apresentados os valores médios mensais de temperaturas e precipitações ocorridas durante o experimento (COOXUPÉ, 2005).

Os dados obtidos foram submetidos à análise de variância (teste F), usandose o programa estatístico Estat (UNESPJaboticabal - SP). As médias foram comparadas pelo teste de Tukey (5\%).

\section{RESULTADOS E DISCUSSÃO}

O período do experimento (março a agosto) foi caracterizado por meses com grandes oscilações de precipitação. Verificou-se, no mês de maio, um elevado valor de precipitação $(169,0 \mathrm{~mm})$, seguido dos meses de junho e julho, com 35,0 e 49,4 milímetros, respectivamente, fato atípico para o período. As temperaturas máximas oscilaram de 14 a $32^{\circ} \mathrm{C}$ e as mínimas de 4 a $20^{\circ} \mathrm{C}$ (COOXUPÉ, 2005).

O ciclo da cultura foi de 172 dias, sendo superior ao normalmente encontrado para as cultivares estudadas. Esse ciclo pode ter sido alterado pelo excesso de água no solo porque, durante o experimento, observou-se um volume total de 422,6 mm, ocasionado pelas 
precipitações. O excesso de água no solo proporciona um prolongamento do crescimento das folhas (Ferreira, 2000) e atrasa o processo de maturação (Maluf, 1999). Conforme Riekels (1977), esse atraso é da ordem de 5 a 19 dias, porém Maluf (1999) afirma que este é de, no mínimo, 20 dias.

A temperatura máxima média variou de 23 a $27,1^{\circ} \mathrm{C}$ e a mínima de 9 a $16,8^{\circ} \mathrm{C}$. Verificaram-se, durante o experimento, 34 dias com temperaturas abaixo de $10^{\circ} \mathrm{C}$, as quais também contribuíram para o prolongamento do ciclo. Temperaturas ideais para a bulbificação estão entre 15 e $25^{\circ} \mathrm{C}$; ocorrendo temperaturas abaixo de $15^{\circ} \mathrm{C}$, a bulbificação torna-se tardia (Blank et al., 1997; Maluf, 1999; Costa et al., 2002).

A produtividade de bulbos foi influenciada somente pelo fator cultivar (Tabela 1). A cultivar Superex (68,9 t $\mathrm{ha}^{-1}$ ) produziu $33,1 \%$ a mais que a cultivar Princesa $\left(51,7 \mathrm{t} \mathrm{ha}^{-1}\right)$, denotando menor capacidade produtiva desta última. Essas produtividades são bem maiores que a média brasileira $\left(20,0 \mathrm{t} \mathrm{ha}^{-1}\right) \mathrm{e}$ do estado de São Paulo (28,0 t ha-1) (FNP Consultoria e Comércio, 2005). Na região de São José do Rio Pardo, onde o experimento foi conduzido, boas produtividades estão em torno de $45 \mathrm{t} \mathrm{ha}^{-1}$ (Vargas, 2005).

Não houve diferença estatística do fator espaçamento entre covas para produtividade (Tabela 1). As produções encontradas ficaram entre $57,1 \mathrm{tha}^{-1}(14$ $\mathrm{cm})$ e $62,0 \mathrm{t} \mathrm{ha}^{-1}(8 \mathrm{~cm})$. Dados semelhantes foram encontrados por Reghin et al. (2004), com a cultivar Crioula e utilizando quatro espaçamentos $(5 ; 8 ; 11$ e $14 \mathrm{~cm}$ ), onde os autores observaram que não houve diferenças significativas na produção final. Nesse mesmo trabalho, a maior produção foi da cultivar Bola Precoce quando em menor espaçamento entre plantas $(5 \mathrm{~cm})$, demonstrando, assim, que há comportamento diferenciado entre genótipos quando se altera a densidade de plantio. De modo semelhante, Coelho et al. (1996) não encontraram diferenças significativas para produção total de bulbos, quando trabalharam com cinco espaçamentos $(0,30 \mathrm{~m} \times 0,08 \mathrm{~m} ; 0,20 \mathrm{~m}$ x $0,08 \mathrm{~m} ; 0,10 \mathrm{~m}$ x $0,08 \mathrm{~m} ; 0,15 \mathrm{~m} \mathrm{x}$ $0,10 \mathrm{~m}$ e $0,10 \mathrm{~m} \times 0,10 \mathrm{~m}$ ) na região de
Tabela 1. Valores médios para a produtividade de bulbos, em função de cultivares, espaçamento entre covas e mudas por célula de bandeja, valores de F, significância e coeficientes de variação (Average values for the yield of bulbs, as a result of cultivars, spacing among holes and plantlets in each tray cell, F values, significance and variation coefficients). Jaboticabal, UNESP, 2004.

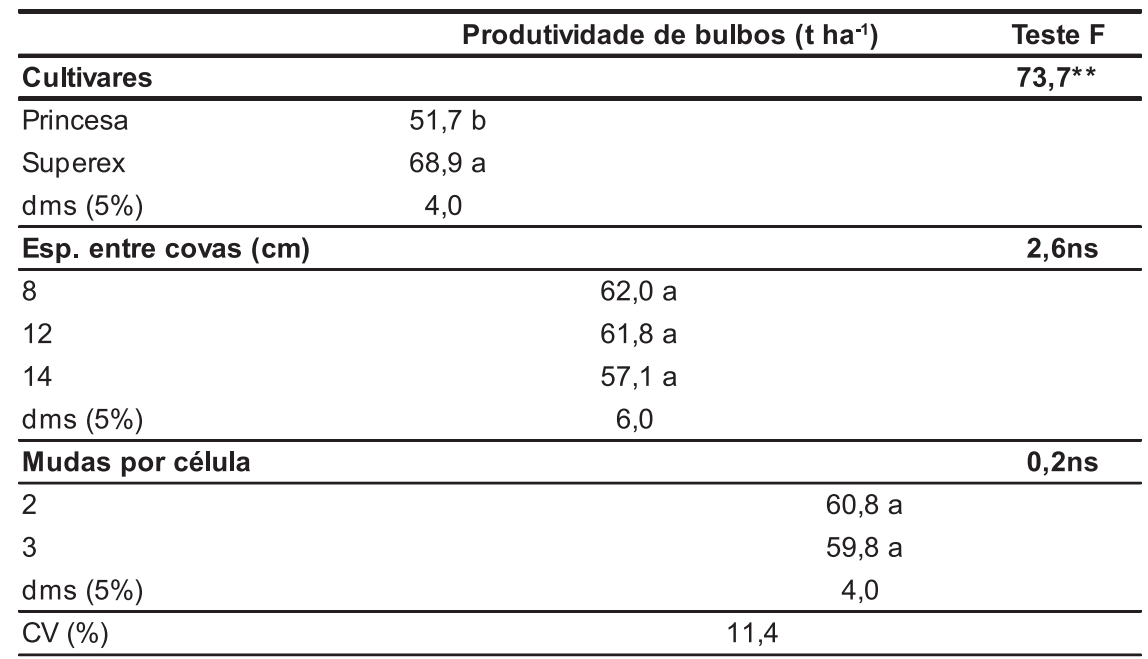

Médias seguidas pela mesma letra coluna não diferem entre si pelo teste Tukey ao nível de $5 \%$ de probabilidade; ns, $* *$ respectivamente, não significativo a $5 \%$ de probabilidade e significativo a $1 \%$ de probabilidade pelo Teste $\mathrm{F}$ (Means followed of same letter in the column did not differ through the Tukey test $(\mathrm{p} \leq 0,05) \mathrm{ns}$, **respectively, non-significative on the level of $5 \%$ probalility and, $1 \%$ probability through the $\mathrm{F}$ test).

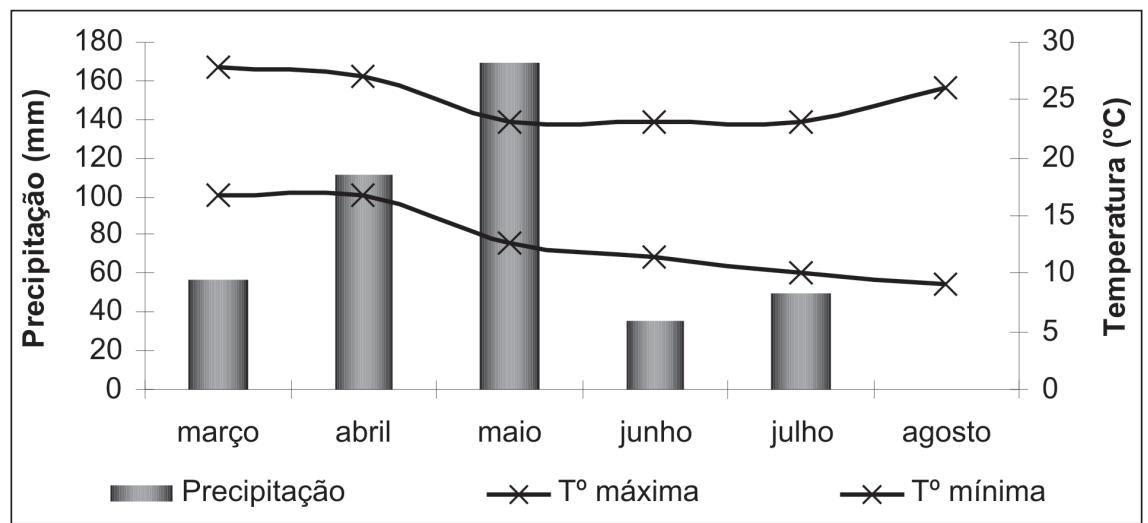

Figura 1. Precipitações pluviométrica $(\mathrm{mm})$ e médias das temperaturas máximas e mínimas, no município de São José do Rio Pardo, durante o período de realização do experimento (Pluviometric rainfall $(\mathrm{mm})$ and average of maximum and minimum temperatures, in São José do Rio Pardo, during the experiment conduction). Jaboticabal, UNESP, 2004.

Parnaíba (PI). Todavia, Siqueira et al. (2004) verificaram diferenças na produtividade quando se alterou a densidade de plantas $(0,30 \mathrm{~m}$ x $0,07 \mathrm{~m}$ a $0,20 \mathrm{~m}$ x $0,07 \mathrm{~m}$ ), pois, à medida que houve diminuição do espaçamento, aumentou-se a produtividade.

Não houve diferença estatística do número de mudas por célula de bandeja (Tabela 1) sobre a produtividade, o que concorda com os resultados de Herison et al. (1993), que estudaram o efeito de uma, duas e três plantas por célula e não encontraram diferenças para produtividade.

Para a massa do bulbo, houve efeito significativo para todos os fatores estudados isoladamente, com interação significativa entre "cultivares" vs. "espaçamento entre covas" e "número de plantas por célula" vs. "espaçamento entre covas".

Para a interação "cultivares" vs. "espaçamento entre covas", observouse um aumento na massa de bulbo, em ambas cultivares, à medida que se au- 
Tabela 2. Valores médios para a massa de bulbos, em função da interação entre espaçamento entre covas vs. cultivares e espaçamento entre covas vs. mudas por célula de bandeja (Average values for bulbs mass, as a result of the interaction among holes spacing and cultivars and, among holes spacing and number of plantlets in each hole of the tray). Jaboticabal, UNESP, 2004.

\begin{tabular}{|c|c|c|c|c|c|}
\hline \multirow{3}{*}{$\begin{array}{l}\text { Espaçamento } \\
\text { entre covas }\end{array}$} & \multicolumn{2}{|c|}{ Cultivares } & \multicolumn{2}{|c|}{ Mudas por célula } & \multirow{3}{*}{ dms $(5 \%)$} \\
\hline & Princesa & Superex & 2 & 3 & \\
\hline & \multicolumn{4}{|c|}{ Massa de bulbo $(\mathrm{g})$} & \\
\hline 8 & $73,9 \mathrm{Bc}$ & $90,5 \mathrm{Ac}$ & $99,7 A c$ & $64,7 \mathrm{Bb}$ & 14,2 \\
\hline 12 & $106,5 \mathrm{Bb}$ & $150,5 \mathrm{Ab}$ & $150,9 \mathrm{Ab}$ & $106,0 \mathrm{Ba}$ & 14,2 \\
\hline 14 & $138,2 \mathrm{Ba}$ & $168,7 \mathrm{Aa}$ & $185,3 \mathrm{Aa}$ & $121,6 \mathrm{Ba}$ & 14,2 \\
\hline $\mathrm{dms}(5 \%)$ & 17,1 & 17,1 & 17,1 & 17,1 & \\
\hline CV (\%) & \multicolumn{4}{|c|}{11,5} & \\
\hline
\end{tabular}

Médias seguidas pela mesma letra maiúscula na linha e minúscula na coluna não diferem entre si pelo teste Tukey ao nível de $5 \%$ de probabilidade. (Means followed of same capital letter in the line and little letter in the column did not differ through the Tukey test $(\mathrm{p} \leq 0,05)$

mentou o espaçamento entre covas. Dentro do intervalo estudado, as cultivares apresentaram maior massa no espaçamento entre covas de $14 \mathrm{~cm}$, sendo 138,2 g e $168,7 \mathrm{~g}$, respectivamente para 'Princesa' e 'Superex'. Independentemente do espaçamento entre covas utilizado, a cultivar Superex sempre se mostrou superior à 'Princesa' (Tabela 2). Desta forma, à medida que ocorreu aumento no espaçamento entre covas, ocorreu aumento na massa do bulbo, fato também verificado por HatridgeEsh \& Bennett (1980), Stofella, (1996) e Reghin et al. (2004). Santos et al. (2000) também verificaram redução significativa na massa do bulbo com o aumento da densidade de plantas. No entanto, os autores encontraram reflexos negativos do aumento da densidade na produtividade, diminuindo de 42,4 para $26,2 \mathrm{t} \mathrm{ha}^{-1}$ nos espaçamentos de 5 e 15 $\mathrm{cm}$, respectivamente, o que difere dos resultados do presente trabalho. Provavelmente, porque os espaçamentos utilizados pelos autores sejam superiores $(5,10$ e $15 \mathrm{~cm}$ entre plantas) ao deste trabalho, não foram observados perdas na produtividade quando se alterou o espaçamento entre covas. Reghin et al. (2004) verificaram, em Ponta Grossa (PR), que o rendimento total de bulbos de cebola é aumentado de acordo com o incremento na densidade de plantas. No entanto, o tamanho de bulbos ou a massa de bulbo diminuem. Rumpel \& Felczynski (2000) também verificaram que a produção de bulbos graúdos é gradativamente decrescente com o aumento da população de plantas. Os maiores bulbos foram produzidos nas populações de 20 a 40 plantas $\mathrm{m}^{-2}$, enquanto os menores foram obtidos na população de 140 plantas $\mathrm{m}^{-2}$.

Para a interação "número de mudas por célula" vs. "espaçamento entre covas", verificou-se aumentos significativos na massa de bulbo à medida que se aumentou o espaçamento entre covas, exceto quando se elevou o espaçamento de 12 para $14 \mathrm{~cm}$ utilizando 3 mudas por célula de bandeja (Tabela 2). Independentemente do espaçamento entre covas utilizado, os bulbos produzidos com duas mudas por célula de bandeja tiveram maior massa que aqueles produzidos com três mudas por célula de bandeja. A maior massa de bulbo, dentro do intervalo estudado, foi encontrada com duas mudas por célula de bandeja, no espaçamento de $14 \mathrm{~cm}$ entre covas (185,3 g).

Com o aumento do número de mudas por célula, juntamente com a diminuição dos espaçamentos entre covas, observou-se que houve maior competição entre as plantas, proporcionando reduções significativas na massa do bulbo. De acordo com Rabinovich \& Brewster (1990), com o desenvolvimento da cultura, a competição entre plantas por luz e nutrientes aumenta, alterando o processo de bulbificação. Para qualquer número de mudas por célula estudada, houve incremento na massa do bulbo com o aumento no espaçamento entre covas.

Conclui-se que a cultivar Superex apresentou maior produtividade em relação à 'Princesa' e que a maior massa de bulbo foi obtida no espaçamento en- tre covas de $14 \mathrm{~cm}$ com duas mudas por célula de bandeja em ambas cultivares.

\section{AGRADECIMENTOS}

O primeiro autor expressa seus agradecimentos à CAPES pela concessão da bolsa de estudos e ao Sr. Adriano Quilises, pela concessão da área e apoio para a realização do experimento.

\section{REFERÊNCIAS}

BLANK AF; SOUZA RJ; PEREIRA AJ. 1997. Cultura da cebola. Lavras: UFLA. 24 p. (Boletim Técnico, 17).

CARDOSO AII; COSTA CP. 1999. Produção de bulbilhos de cebola em bandejas de isopor. Scientia Agrícola 56: 969-974.

COELHO EF; SOUZA VAB; CONCEIÇÃO MAF. 1996. Comportamento da cultura da cebola em três regimes de irrigação e cinco espaçamento. Pesquisa Agropecuária Brasileira 31: 585-591.

COOXUPÉ - COOPERATIVA DOS CAFEICULTORES DE GUAXUPÉ. 2005, 4 de fevereiro. Dados climáticos. Disponível em: <https:/ /www.cooxupe.com.br/meteorologia/ 2004.htm>.

COSTA ND; LEITE DL; SANTOS CAF; CANDEIA JA; VIDIGAL SM. 2002. Cultivares de cebola. Informe Agropecuário 218: 20-27.

FERREIRA MD. 2000. Cultura da cebola: recomendações técnicas. Asgrow Seed Company, $36 \mathrm{p}$.

FNP Consultoria \& Comércio. 2005. Anuário Estatístico da Agricultura Brasileira AGRIANUAL-2005. São Paulo. 521p.

FONTES PCR; SILVA DJH. 2002. Métodos de Produção de cebola. Informe Agropecuário 218: 28-35.

HATRIDGE-ESH KA; BENNETT JP. 1980. Effects of seed weight, plant density and spacing on yield responses of onion. Journal of Horticultural Science 55:247-252.

HERISON C; MASABNI JG; ZANDSTRA BH. 1993. Increasing seedling density, age, and nitrogem fertilization increases onion yield. Hortscience 28:23-25.

MALUF WR. 1999. Melhoramento de cebola (Allium cepa L.). Lavras: UFLA. 17p. (Apostila).

MAY A. 2006. Desempenho de híbridos de cebola em função da população de plantas e fertilização nitrogenada e potássica. Jaboticabal: UNESP. 142f (Tese doutorado).

MINAMI K; TESSARIOLI NETTO J. 1994. Cultura da cebola. Piracicaba: SEBRAE/ESALQ. 46p. (Cursos agrozootécnicos).

NICHOLS MA. 1967. A note on a plant density and fertilizer experiment with onions in New Zealand. Horticultural Research 7:144-147.

RABINOVICH HD; BREWSTER JL. 1990. Onion and allied crops. Boca Raton: CRC Press. 273p. 
REGHIN MY; OTTO RF; JACOBY CFS; OLINIK JR; OLIVEIRA RP. 2004. Efeito da densidade de plantas no rendimento de bulbos com diferentes cultivares de cebola. In: $\mathrm{CON}$ GRESSO BRASILEIRO DE OLERICULTURA, 44. Resumos... Campo Grande: SOB (CD-ROM).

RIEKELS JW. 1977. Nitrogen-water relationships of onion grown on organic soil. Journal of the American Society for Horticultural Science 102: 139.

RUMPEL J; FELCZYNSKI K. 2000. Effect of plant density on yield and bulb size of direct sown onions. Acta Horticulturae 533: 179-186.

SANTOS HS; TANAKA MT; WATANABE SH; ARANTES PAZ; IVONE TT. 2000. Produção de cebola em função de tamanho de muda e espaçamento. In: CONGRESSO BRASILEIRO DE OLERICULTURA, 40. Anais... São Pedro: SOB. p.556-557.
SEMINIS VEGETABLE SEEDS DO BRASIL SEMENTES LTDA. s.d.. Princesa. Campinas. SIQUEIRA LG; REBOUÇAS TNH; VIANA AES; GRISE FA; MENDONÇA JL; VIDIGAL SM. 2004. Densidade de plantio em transplante de mudas de cebolas, cultivar Serrana e híbrido Mercedes. In: CONGRESSO BRASILEIRO DE OLERICULTURA, 44. Resumos... Campo Grande: SOB (CD-ROM).

STOFFELLA PJ. 1996. Planting arrangement and density of transplants influence sweet spanish onion yields and bulbs size. Hortscience 31: 1129-1130.

TAKII DO BRASIL LTDA. s.d. Superex. São Paulo.

TRANI PE; TAVARES M; SIQUEIRA WJ. 1996. Cebola (sistema de mudas). In: RAIJ B van; CANTARELLA H; QUAGGIO JA;
FURLANI AMC (eds). Recomendações de adubação e calagem para o estado de São Paulo. Campinas-SP: IAC, p.176. (Boletim Técnico 100).

VARGAS PF. 2005. Produtividade e classificação de bulbos de cebola em função de diferentes densidades e distribuição espacial. Jaboticabal: UNESP. 59f (Tese de mestrado).

VIDIGAL SM; FACION CE; PACHECO DD 2002. Avaliação de cultivares de cebola na região norte de Minas Gerais. In: CONGRESSO BRASILEIRO DE OLERICULTURA, 42 Resumos... Campo Grande: SOB (CD-ROM). 